\title{
Study on Failure Law of Mining Process of Narrow Coal Pillars in Fully Mechanized Caving Roadway
}

\author{
Haifeng Ren, Xuewen Zhao* and Peng Cao \\ School of Safety Science and Engineering, Xi' an University of Science and Technology, Xi' an 710054, China
}

\begin{abstract}
In order to determine the damage law of narrow coal pillars in the roadway along the goaf, taking the 4-5(06) working face of a mine in Xinjiang as the research object, the 3D finite difference software FLAC3D is used to analyse the stress and displacement distribution characteristics of narrow coal pillars in the mining process. The results show that the internal stress of the coal pillar reaches the peak when the narrow coal pillar advances from $11 \mathrm{~m}$ to $12 \mathrm{~m}$, and the coal pillar is subjected to the pre-supporting pressure, the range of the rupture zone is increased, and the bearing capacity is obviously reduced. When the working face advances $65 \mathrm{~m}$, the displacement in the coal column reaches a peak, and the deformation of the coal column is more serious. The field test results show that the damage law of the narrow coal pillars in the working face mining process is basically consistent with the simulation results. After the bolts, the cable-stayed anchor cable and the shotcrete, the deformation of the narrow coal pillar is in a controllable range, and the safety production requirements of the working face are realized.
\end{abstract}

\section{Introduction}

With the continuous improvement of coal mining technology, the shallow coal resources are gradually exhausted, and most of the coal mines have entered the deep mining stage [1]. In order to improve the coal recovery rate, narrow coal pillars along the goaf are widely used in deep mines [2-4]. J B Bai [5-8] and so on, through the theoretical analysis method, the structural mechanics model of the roadway along the goaf is created. Z P Shen [9] studied the internal stress state of the narrow coal pillar, the influence range of the supporting stress and the surrounding rock of the roadway, which proposes a feasible method for the retention of reasonable coal pillar width. C T Hou [10] obtained the deformation and instability law of surrounding rock in the roadway along the goaf through the principle of large deformation and small structure stability of the surrounding roadway in fully mechanized top coal caving. However, at present, there are few studies on the damage law of narrow coal pillars during the mining process of fully mechanized caving face along the goaf.

Taking the 4-5 (06) working face of a mine in Xinjiang as an example, the FLAC3D numerical simulation software is used to simulate the stress and displacement distribution of narrow coal pillars during the mining process, the distribution of stress and displacement in coal pillars is analyzed. It provides a reference for the stability and control technology of narrow coal pillars in the mining process along the goaf.

\section{Project overview}

The working face of a mine (4-5) 06 in Xinjiang has a length of $180 \mathrm{~m}$, a strike length of $1850 \mathrm{~m}$, a coal seam inclination of $25^{\circ}$ to $33^{\circ}$, an average of $29^{\circ}$, and an average coal seam thickness of $6.15 \mathrm{~m}$. The direct top is mainly siltstone and mudstone with an average thickness of $10.5 \mathrm{~m}$ (4-5) 06 working face and the upper section 4-5 (04) working face (completed) separated by a narrow coal pillar $4 \mathrm{~m}$ wide, the working surface position relationship, as shown in Figure 1.

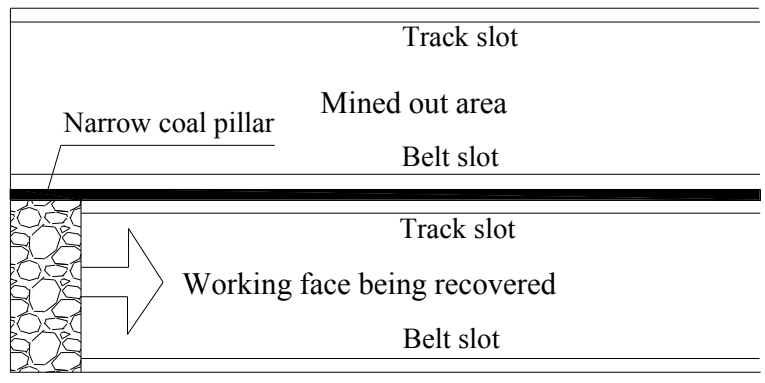

Figure 1. Working face position diagram

\section{Model establishment}

According to the relationship between the top and bottom rock layers of the working face of 4-5(06) and the thickness of the rock formation, the 3D numerical calculation model and the number of rock layers can be determined. The parameters such as the thickness and 
relationship of each rock layer are shown in Table 1.

Table 1. Rock formation relationship

\begin{tabular}{ccc|ccc}
\hline Number & Layer & Thickness & Number & Layer & Thickness \\
\hline & & & 8 & Siltstone & $6 \mathrm{~m}$ \\
15 & Sandy mudstone & $30 \mathrm{~m}$ & 7 & Fine sandstone & $2.89 \mathrm{~m}$ \\
14 & Siltstone & $3 \mathrm{~m}$ & 6 & Mudstone & $4 \mathrm{~m}$ \\
13 & Mudstone & $3 \mathrm{~m}$ & 5 & Coal & $6.15 \mathrm{~m}$ \\
12 & Fine sandstone & $6 \mathrm{~m}$ & 4 & Coarse sandstone & $2 \mathrm{~m}$ \\
11 & Siltstone & $5 \mathrm{~m}$ & 3 & Siltstone & $3 \mathrm{~m}$ \\
10 & Coarse sandstone & $5 \mathrm{~m}$ & 2 & Mudstone & $3 \mathrm{~m}$ \\
9 & Middle sandstone & $4 \mathrm{~m}$ & 1 & Sandy mudstone & $30 \mathrm{~m}$ \\
\hline
\end{tabular}

The calculation model range is $400 \mathrm{~m} \times 300 \mathrm{~m} \times 300 \mathrm{~m}$, and the model failure feature is defined as the MohrCoulomb model. The parameters of the coal seam roof and floor rock formation are shown in Table 2. The model gravity acceleration is set to $9.8 \mathrm{~m} / \mathrm{s}^{2}$. The boundary conditions are set such that the model limits horizontal movement, the bottom is fixed, and the upper boundary applies a load of 10MPa. The model is built as shown in Figure 2.

Table 2. Coal seam top floor rock layer parameters

\begin{tabular}{lccccccc}
\hline Position & Lithology & $\begin{array}{c}\text { Bulk density } \\
/ \mathrm{kNm}^{-3}\end{array}$ & $\begin{array}{c}\text { Elastic } \\
\text { Modulus } / \mathrm{Mpa}\end{array}$ & $\begin{array}{c}\text { Poisson } \\
\text { ratio } / \mathrm{p}\end{array}$ & $\begin{array}{c}\text { Cohesive } \\
\text { force } / \mathrm{Mpa}\end{array}$ & $\begin{array}{c}\text { Dilatancy } \\
\text { angle } /\left(^{\circ}\right)\end{array}$ & $\begin{array}{c}\text { Internal friction } \\
\text { angle } /\left(^{\circ}\right)\end{array}$ \\
\hline \multirow{4}{*}{ Roof } & Mudstone & 20.80 & 20019 & 0.195 & 0.93 & 8 & 31 \\
& Middle sandstone & 26.60 & 50430 & 0.28 & 2.27 & 10 & 31 \\
\multirow{4}{*}{ Coal } & Fine sandstone & 26.20 & 43020 & 0.26 & 1.93 & 10 & 31 \\
\multirow{2}{*}{ Floor } & Siltstone & 26.00 & 54739 & 0.253 & 1.3 & 12 & 35 \\
& Coal & 14.60 & 14142 & 0.275 & 0.72 & 8 & 20 \\
& Coarse sandstone & 26.40 & 56767 & 0.278 & 1.38 & 8 & 34 \\
\hline
\end{tabular}

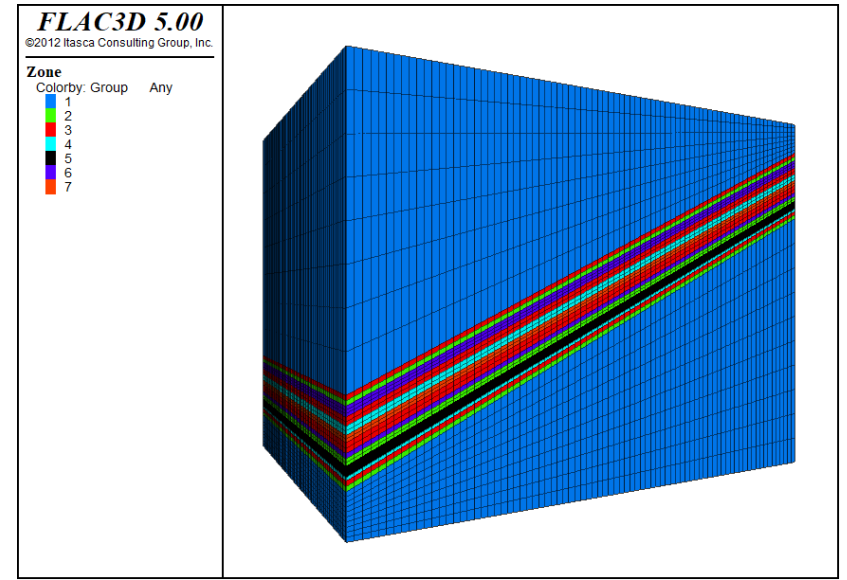

Figure 2. Numerical calculation model

\section{Simulation results analysis}

\subsection{Vertical stress distribution characteristics of narrow coal pillars along goaf}

Figure 3 shows the vertical stress distribution in narrow coal pillars during the mining process. 


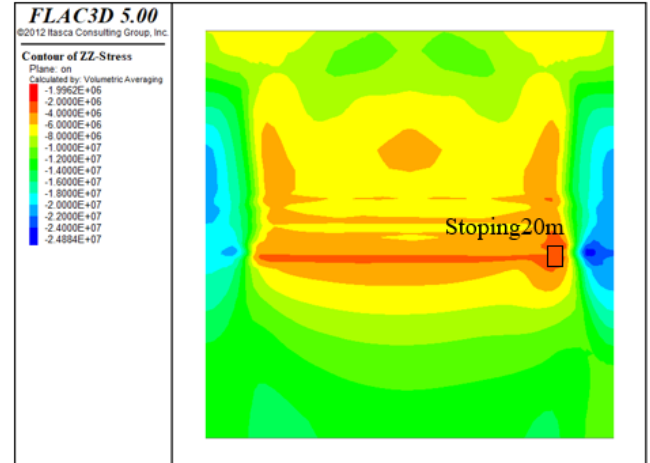

(a) $20 \mathrm{~m}$

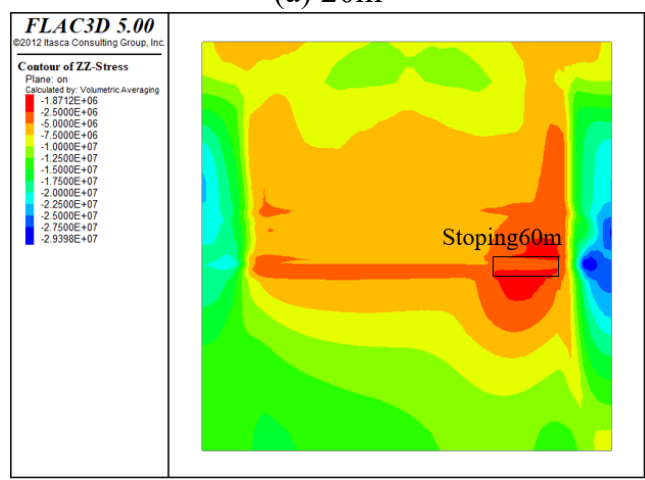

(c) $60 \mathrm{~m}$

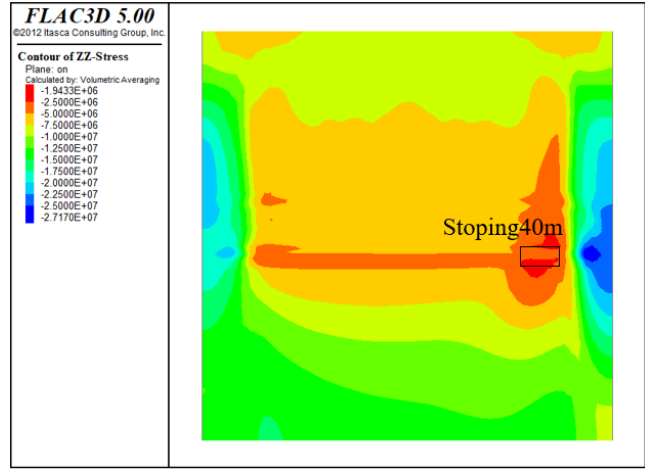

(b) $40 \mathrm{~m}$

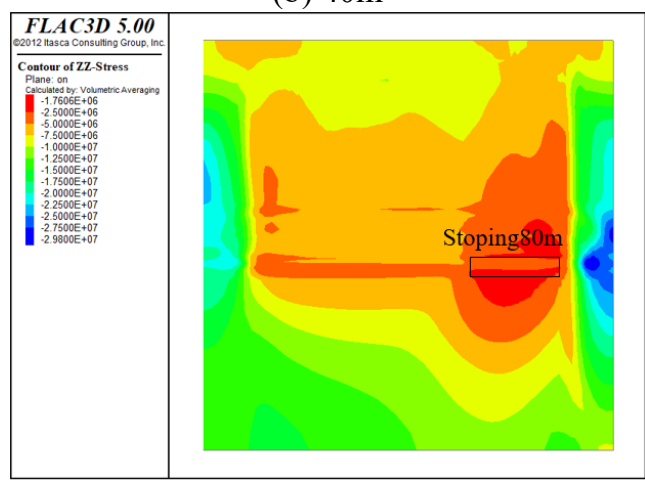

(d) $80 \mathrm{~m}$

Figure 3. Distribution of vertical stress field of narrow coal pillar during mining

It can be seen from Figure 3 that during the mining process of the working face, the roadway along the goaf is subjected to the pre-supporting pressure, and there is a large stress concentration phenomenon in the narrow coal pillar. When the concentrated stress exceeds the pressure that the narrow coal pillar can withstand, plastic

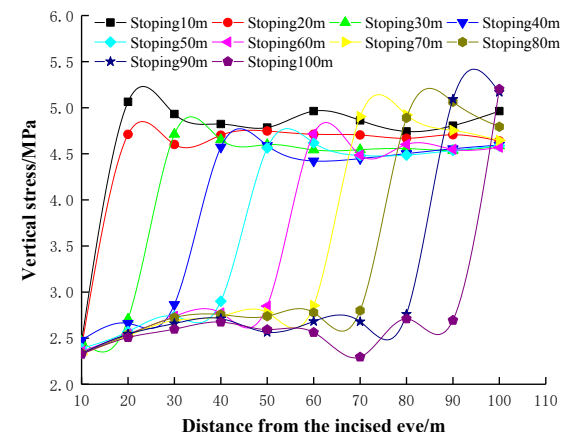

Figure 4. Vertical stress distribution in coal pillar during mining

It can be seen from Figure 4 and Figure 5 that the vertical stress distribution of the coal pillar has the following characteristics: The vertical stress in the coal pillar is basically linear and stable before the peak of the stress. When the working face is in advance of $11 \mathrm{~m}-12 \mathrm{~m}$, the stress peaks quickly and then tends to be stable. The change of stress peak is: When the distance from the cutting eye is $22 \mathrm{~m}$, the vertical stress in the coal pillar is lower and the bearing capacity is higher. With the increase of the propulsion distance, the peak vertical stress growth rate in the coal pillar is relatively fast, and the bearing capacity of the coal pillar is obviously weakened. deformation occurs, and the degree of plastic damage in the coal pillar increases.

According to the numerical calculation results, the stress variation in the narrow coal pillar during the mining process of the working face can be obtained, as shown in Figure 4.

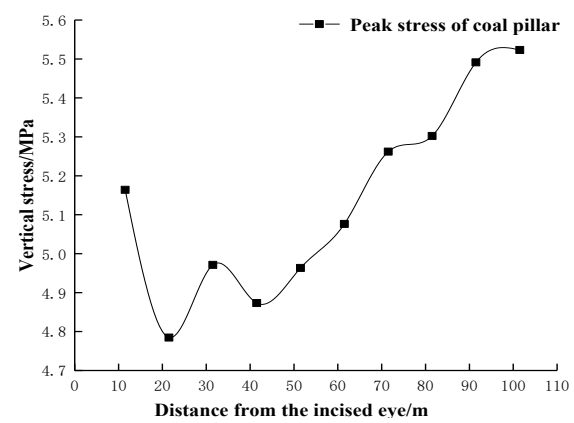

Figure 5. Peak distribution of vertical stress in coal pillar

In summary, during the mining process, the vertical stress in the coal pillar reaches a peak at $11 \mathrm{~m}-12 \mathrm{~m}$ from the working face, the coal pillar completely undergoes plastic failure, the bearing capacity is low, and there is no stable bearing area. After $20 \mathrm{~m}$ from the working face, the stress on the coal pillar tends to be stable, and the stability in the coal pillar is obvious. Therefore, from the coal pillar stability analysis, when the working face is $11 \mathrm{~m}-12 \mathrm{~m}$ away, the narrow coal pillar needs to strengthen the advanced support. 


\subsection{Vertical displacement distribution characteristics of narrow coal pillars along goaf}

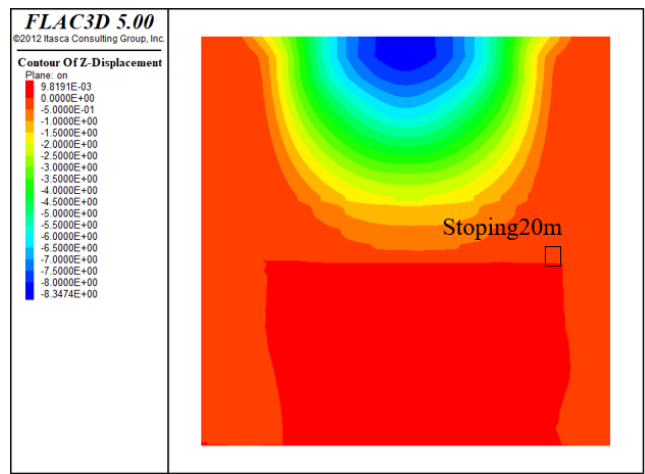

(a) $20 \mathrm{~m}$

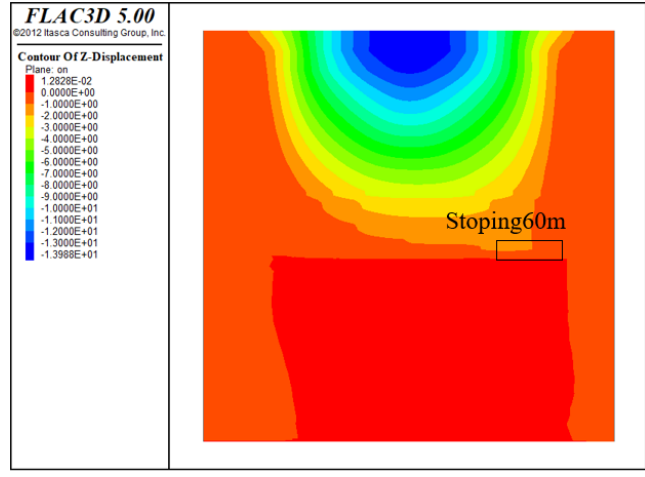

(c) $60 \mathrm{~m}$
Figure 6 shows the vertical displacement distribution in narrow coal pillars during the mining process.

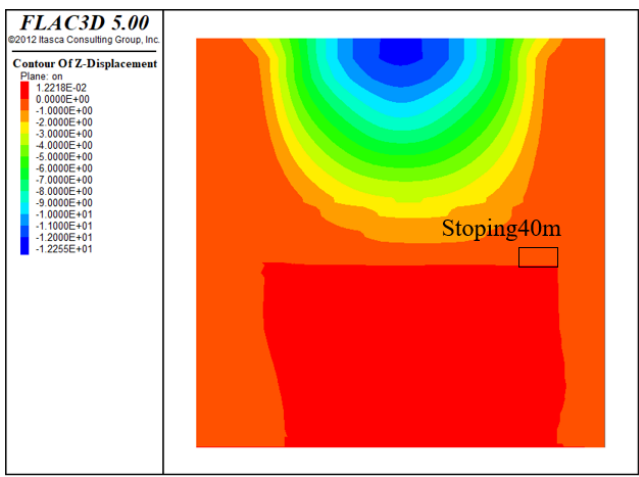

(b) $40 \mathrm{~m}$

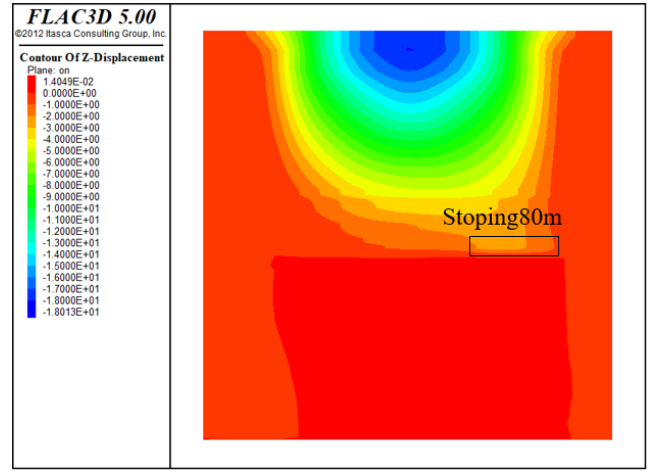

(d) $80 \mathrm{~m}$

Figure 6. Vertical displacement field distribution of narrow coal pillars during mining

It can be seen from Figure 6 that with the advancement of the working face, the displacement of the overlying strata of the narrow coal pillar increases gradually, and the displacement distribution patterns of different propulsion periods have obvious differences. During the process of propelling the working face $40 \mathrm{~m}$, the displacement of the coal pillar does not change significantly. When the working face advances $50 \mathrm{~m}$, the displacement distribution pattern of the narrow coal pillar begins to change. When the working face is propelled by $60 \mathrm{~m}-70 \mathrm{~m}$, the narrow coal pillars in the goaf suddenly appear large displacement, and the narrow coal pillars are crushed. It can be known that the periodic pressure of working face is in the process of $60 \mathrm{~m}-70 \mathrm{~m}$.

According to the numerical calculation results, the stress variation in the narrow coal pillar during the mining process of the working face can be obtained, as shown in Figure 7.

It can be seen from Figure 7 that the vertical displacement distribution of the narrow coal pillar has the following variation law:

In the process of propelling the working face, the vertical displacement of the coal pillar is small at first, and the range distribution is also small. During the process of propelling the working surface from $10 \mathrm{~m}$ to $40 \mathrm{~m}$, the vertical displacement of the coal pillar is small and tends to be stable, and the displacement is $0.1 \mathrm{~cm}-0.3 \mathrm{~cm}$. As the working face continues to advance, due to the disturbance of mining, the vertical displacement of the thick coal pillar overburden gradually increases, and the influence range also increases, and gradually moves forward. When the working surface is advanced to $65 \mathrm{~m}$, the vertical displacement of the narrow coal pillar increases significantly and reaches the displacement peak.

In summary, in the mining process, when the working surface is propelled by $10 \mathrm{~m}-40 \mathrm{~m}$, the vertical displacement of the coal pillar is small, the coal pillar bearing capacity is high, and the coal pillar is relatively stable. When the working surface advances $65 \mathrm{~m}$, at this time, the cycle is pressed at $65 \mathrm{~m}$, and the coal pillar deformation is serious. Therefore, from the coal pillar stability analysis, when the working face is advanced by $65 \mathrm{~m}$, the narrow coal pillar needs to be strengthened.

\section{Engineering practice}

During the mining of 4-5(06) working face, the deformation of the roof of the roadway along the goaf and the moving amount of the roadway are monitored on site. The displacement measuring points are arranged at the front working face $150 \mathrm{~m}$, and the data of the deformation of the surrounding rock surface of the roadway are recorded and summarized. The change graph of the relationship between the approaching distance and the time of the roadway is shown in Figure 8. 


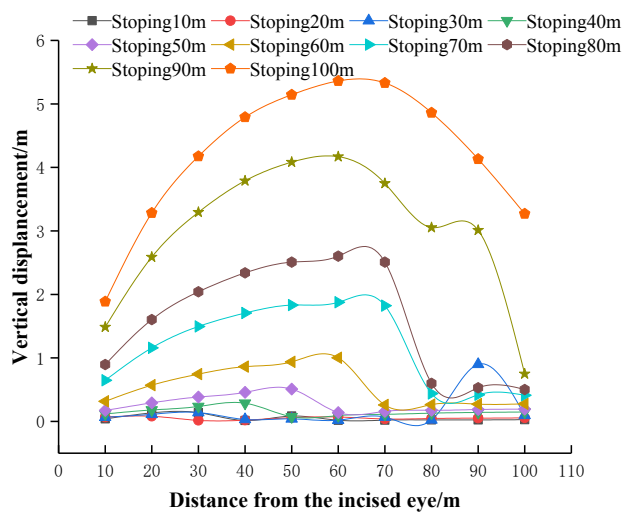

Figure 7. Distribution of vertical displacement in coal pillars during mining

It can be seen from Figure 8 that during the mining process of the 4-5(06) working face, the deformation of the surrounding rock of the roadway gradually increases with the advancement of the working face. Before the arrangement of measuring points $14 \mathrm{~d}$, the moving amount of the roof of the roadway and the amount of movement of the two gangs are small. After $28 \mathrm{~d}$ of the measuring point, the roadway is affected by the pre-stress and the two gangs are affected by the mining. The road surface begins to have a large surface displacement. After the measuring point is arranged for $37 \mathrm{~d}$, the surface displacement of the

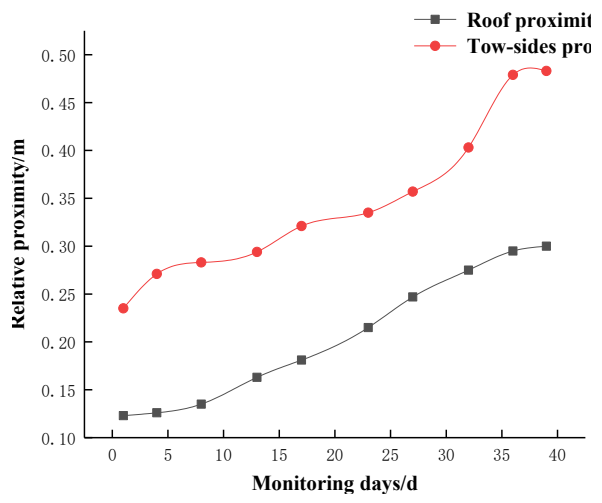

Figure 8. Surface deformation of the roadway during mining

roadway reaches the maximum value of $0.3 \mathrm{~m}$ and $0.48 \mathrm{~m}$.

The roof and two gangs of the roadway are supported by bolts, anchor cables and shotcrete. The layout is shown in Figure 9.

The narrow coal pillar and the close to the narrow coal pillar side roof spray sealing, the spraying process is: Removal of floating coal and anchor net - Flushing roadway - Mixing concrete - Spray concrete - Water spray maintenance. After the shotcrete is completed, the spray section is shown in Figure 10.

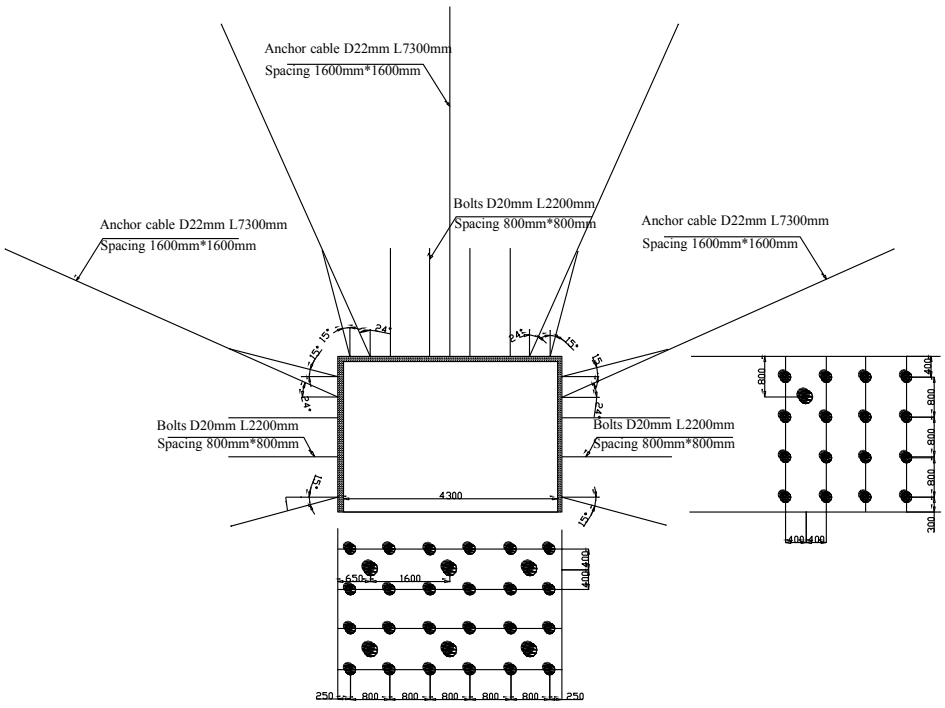

Figure 9. Bolt support section diagram

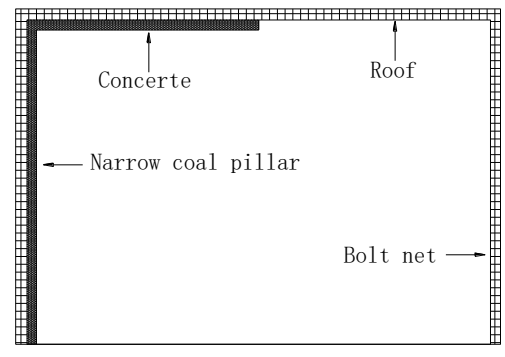

Figure 10. Shotcrete profile
After the support technology such as bolt, cable-stayed anchor and shotcrete, the deformation of the two gangs and the top and bottom of the roadway is effectively controlled, and the deformation of the roadway is within the allowable range, which satisfies the requirement of safe production in working face.

\section{Conclusion}

1) In the mining process of gob-side entry of fully mechanized top-coal caving, when the working face is $11 \mathrm{~m}-12 \mathrm{~m}$ ahead, the stress in the narrow pillar reaches its peak value, and the pillar is completely plastic destroyed, and there is no stable bearing area.

2) In the process of mining the roadway along the goaf of the fully mechanized caving face, when the working face is advanced $65 \mathrm{~m}$, the internal displacement of the narrow coal pillar reaches the peak value. At this time, the working face is in cycle pressure, and the coal pillar is seriously damaged. 
3) Through the on-site surrounding rock deformation monitoring, the information of the roadway feedback is improved and optimized. In the process of mining, it is necessary to do a good job of $11 \mathrm{~m}-12 \mathrm{~m}$ of the leading face of the narrow coal pillar. Local support can be strengthened according to the actual situation. At the same time, reinforce the support at the roadway corner to ensure that the roadway is effectively controlled.

\section{Acknowledgments}

The authors would like to acknowledge the support of the State Key Research Development Program of China (Grant No. 2018YFC0808303).

\section{References}

1. Qian M.G., Xu J.L., Wang J.C. (2018) Rediscussion on the scientific exploitation of coal. Online First Journal of China Coal Society, 43(01):1-13.

2. Bai J.B., Wang W.J., Hou C.T. (2000) Study on control mechanism and support technology of surrounding rock in roadway driving along goaf in fully mechanized caving. Journal of China Coal Society, (05):478-481.

3. Guo J.G., Wang W.G., Yue S.S. (2017) Control mechanism and application of surrounding rock in gateway driving along goaf in ultra-thick coal seam. Journal of China Coal Society, 42(04):825-832.

4. Wang D.C., Wang Q., Li S.C. (2014) Analysis of deformation and failure mechanism of surrounding rock in gob-side excavation in deep mine and its control countermeasures. Journal of Mining and Safety Engineering, 31(05):665-673.

5. Li C.H., Bai J.B. (2019) Study on optimization of coal pillar roadway layout under mining influence. Coal Mine Safety, (08):166-172.

6. Liu Y.C. (2019) Study on support technology of roadway driving along narrow coal pillars in inclined medium thick seam. Coal Mine Modernization, (04):7-9.

7. Chen X.Z., W.M. (2015) Study on deformation characteristics and control technology of surrounding rock in gob in deep inclined coal seam. Journal of Mining and Safety Engineering, 32(03):485-490.

8. Cao S.G., Wang Y., Zou D.J. (2013) Analysis of mechanical model of retaining roadway along inclined coal seam. Journal of Chongqing University, 36(05):143-150.

9. Shen Z.P. (2010) Research and application of coal pillar width and support parameters in roadway driving along goaf. Coal Science and Technology, 38(7):31-33.

10. Hou C.T., Li X.H. (2001) Stability principle of large and small structures of surrounding rocks in fully mechanized caving roadway. Coal Science and Technology, 26(1):1-6. 